\title{
Numerical Simulation for Composite Wing Structure Design Optimization of a Minitype Unmanned Aerial Vehicle
}

\author{
Yan Zhang, Fenfen Xiong and Shuxing Yang*
}

School of Aerospace Engineering, Beijing Institute of Technology, Beijing 100081, China

\begin{abstract}
To improve the structure performances of minitype unmanned aerial vehicle (UAV) wing, numerical simulation and optimization design principle was carried out for designing the best composites wing structure. Thus tradeoff can be obtained between the general performance and the weight of the wing. Advanced composite material has its own outstanding features, such as high specific strength, high specific modulus, designable performance and integral forming easily. The application of advanced composite material on the aerocraft structure can significantly reduce the weight, and improve the aerodynamic and flight performances. In this paper, the parametric finite element model is established using parametric modeling technique for stress and stain analysis. Given any set of geometric parameters, the geometric modeling, meshing, strain and stress analysis can be automatically carried out in sequence. The global optimal solution is guaranteed by the proposed two-step optimization search strategy combing genetic algorithm (GA) and sequential quadratic programming (SQP). Comparative studies show that the optimization efficiency can be greatly improved with the two-step optimization search strategy.
\end{abstract}

Keywords: Advanced composite material, structure design, parametric finite element modeling, optimization design.

\section{INTRODUCTION}

As a kind of new material, the advanced composite material brings about great revolution to the aerocraft industry since it was introduced in the 1960 s. With its wide application in aerospace structure, the advanced composite material is named as "the four main materials of aerospace structure" along with aluminum alloy, titanium alloy, and alloy steel. The advanced composite material has its own prominent features, such as high specific strength, high specific modulus, designable performance and integral forming easily, etc. With the application of the advanced composites, the weight of the aerocraft structure can be reduced by about $25 \% \sim 30 \%$ compared to the conventional metal structures. Moreover, the aerodynamic and flight performances can be improved to the levels that the conventional materials can hardly achieve. The extensive application of advanced composites is also able to promote some further technology development of structure stealth and intelligent structure design. The aerocraft structure performance is significantly dependent on the part and quality of the advanced composites used in aerocraft. However, it is difficult to achieve good designs of the composites in aerocraft structure to guarantee requirements for different missions. Therefore, to fully explore the directional properties of composites, the designable ability of structure performance and the excellent manufacturability of large component integral forming, it is necessary to introduce the principle of optimization to the composite structure design [1-6].

In this paper, the optimization design and numerical simulation for composite structure of wing on a UAV is

*Address correspondence to this author at the Box 14, School of Aerospace Engineering, Beijing Institute of Technology, Beijing 100081, China; Tel: +86-010-68912419(office); Fax: +86-010-68912419;

E-mail: yangshx@bit.edu.cn implemented. By using parametric modeling technique, the parametric finite element model is established to conduct stress and strain analysis of the wing. Given any set of geometric parameters, the geometric modeling, meshing, strain and stress analysis can be automatically carried out in sequence. To ensure the optimal solution can be obtained, a two-step optimization search strategy which combines genetic algorithm (GA) and sequential quadratic programming (SQP) is proposed during optimization. It is concluded that this two-step optimization search strategy can greatly enhance the efficiency of finding the true optimal solution through comparing this method with GA.

\section{THE PARAMETRIC FINITE ELEMENT MODEL- ING OF UAV}

\subsection{Geometric Modeling and Meshing}

Wing box is the main load bearing structure of airfoil surface, including skin panels, beams and core sandwich panel, etc. Aerofoil B-8306-b 5 depicted in Fig. (1) is considered in this work [7]. Fig. (2) displays the geometric model with mesh of the minitype UAV wing. The parameters involved in the geometric modeling process are: the quality of $\mathrm{UAV} W=5 \mathrm{~kg}$, reference area of wing $\mathrm{s}=0.16 \mathrm{~m} 2$, taper ratio $\lambda=0.8$, aspect ration $A=8$, wing span $b$, length of root chord $c_{\mathrm{r}}$, length of tip chord $c_{\mathrm{t}}$, sweepback angle (leading edge sweepback angle $L_{\mathrm{LE}}$, a quarter chord sweepback angle $\left.L_{\mathrm{c} / 4}=10^{\circ}\right)$ and $\mathrm{b}, c_{\mathrm{t}}, L_{\mathrm{LE}}\left(A=\frac{b^{2}}{s}, c_{\mathrm{t}}=\frac{2 s}{b(1+l)}\right.$, $\left.\tan L_{\mathrm{LE}}=\tan L_{\mathrm{c} / 4}+\frac{1-l}{A(1+l)}\right)$. 


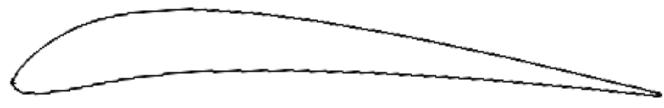

Fig. (1). Aerofoil B-8306-b.

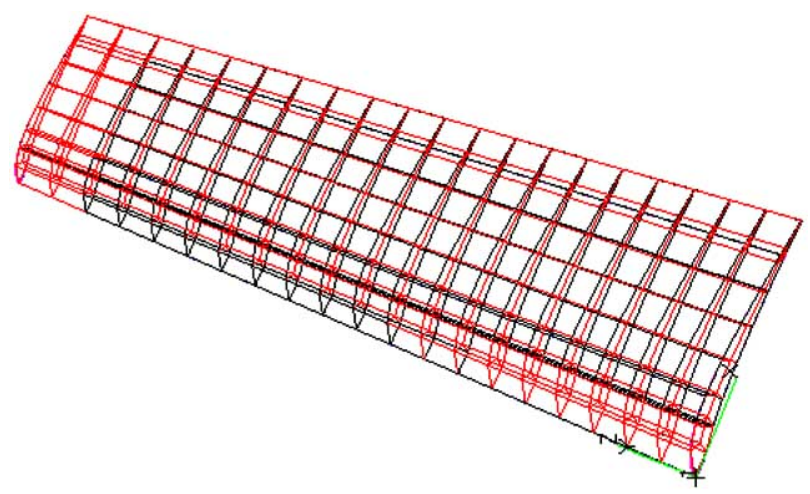

Fig. (2). Geometric model of UAV wing.

\subsection{Finite Element Analytical (FEA) Modeling}

The true pressure distribution of the upper and lower surfaces of the UAV wing is illustrated in Fig. (3) [8]. It is

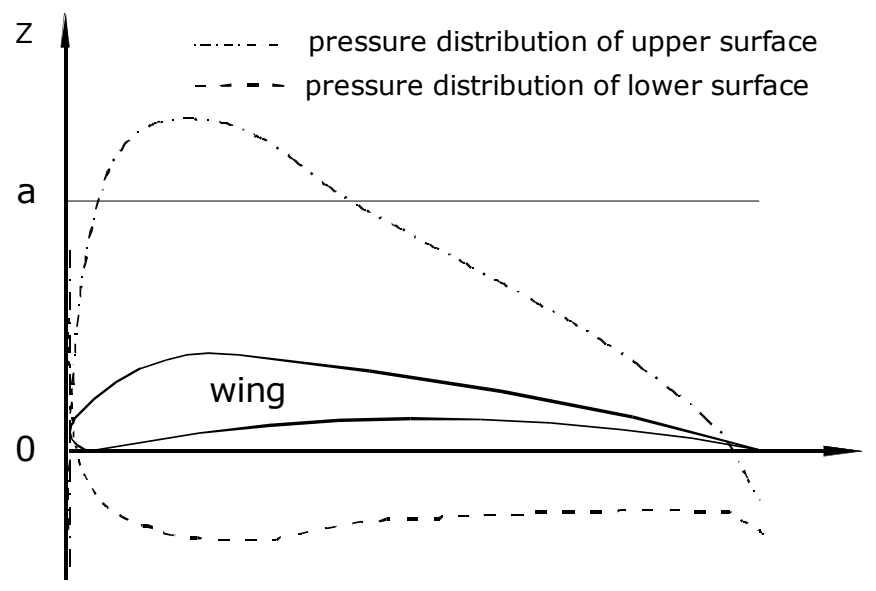

Fig. (3). True load curve.

very difficult to exert such load on the FEA model for practical applications. Therefore, the true load curves in Fig. (3) are simplified within the precision requirement, and the load adopted in this work is shown in Fig. (4). In these Figures, the solid line represents the wing geometry shape, the dash dot line represents the pressure distribution of upper surface of the wing, and the dotted line represents the pressure distribution of lower surface of the wing.

In Figs. (3 and 4), $a$ is a constant coefficient $(a=$ $\left.2.64 \times 10^{-4}\right)$, which can be calculated according to the equilibrium condition of forces between the load suffered by the wing and the weight of UAV. According to the geometric relationship, the chord length of any section can be expressed as $c=c_{\mathrm{b}}-\frac{c_{\mathrm{b}}-c_{\mathrm{t}}}{b / 2} y$. Then the values

determining the pressure distribution of upper and lower surfaces of the wing $\left(\mathrm{z}_{1}, \mathrm{z}_{3}, \mathrm{z}_{2}, \mathrm{z}_{4}\right)$ can be calculated. Because the wing is fixed on the aircraft body, both the displacement and rotation angle at the root chord are considered as zero.

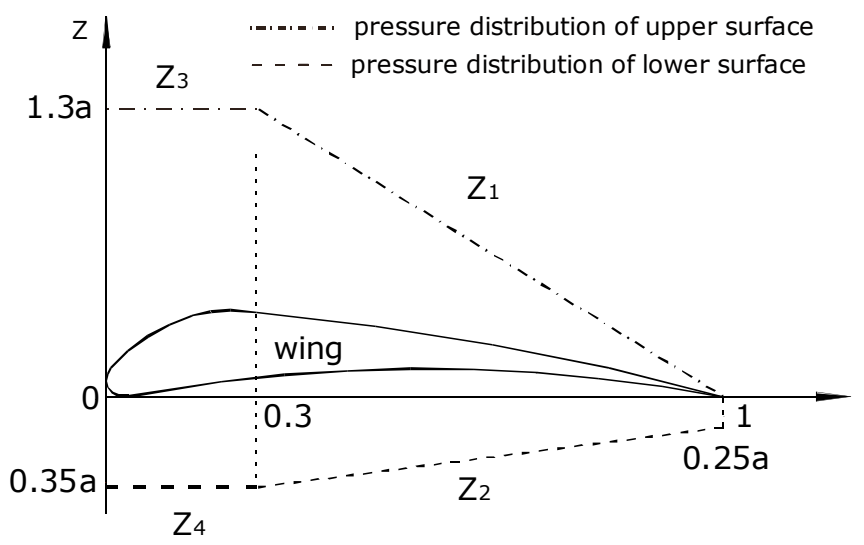

Fig. (4). Approximate load curve.

The material used in the core sandwich panels is foam adhesive, of which the elastic modulus is $\mathrm{E}=5.7 \mathrm{MPa}$, the shear modulus is $\mathrm{G}=3 \mathrm{MPa}$ and the density is $0.04 \mathrm{~g} / \mathrm{cm}^{3}$. The material used for beams is Korean pine, of which the elastic modulus is $\mathrm{E}=10400 \mathrm{MPa}$ and the density is $0.5 \mathrm{~g} / \mathrm{cm}^{3}$. The material used for skin panels is carbon fiber/epoxy resin, of which the single layer sickness is $0.28 \mathrm{~mm}$ and the density is $1.4 \mathrm{~g} / \mathrm{cm}^{3}$. The mechanical properties of unidirectional laminates can be found in Reference [1]. The upper surface of the skin suffers pressure, while the lower surface suffers tension. Meanwhile, carbon fiber is two-dimensional anisotropic, which means that it has different capability to resist tensile and compressive strength. Therefore, in order to achieve the optimal overall performance of the wing, different materials are respectively used in the skin panels in the upper and lower surface. The number of composites layer is considered as the variable $N$, and laying angle equals to $\frac{180^{\circ}}{N}$.

\subsection{Model Parameterization}

To facilitate the design optimization, the parametric model with the geometric parameters as control parameters of the minitype UAV wing is established using the parametric modeling technique in the MSC. Patran software [9]. The automatic process of FEA modeling is called model parameterization. The detailed description of this process is: 1) the design parameters are given by the designers; 2) geometric model are updated according to the current design parameters; 3) the FEA model based on the updated geometric model is automatically rebuilt by the parametric finite element modeling program. Thus the designers can be freed from tedious work full of details design, and concentrate on the control feature of design object without 


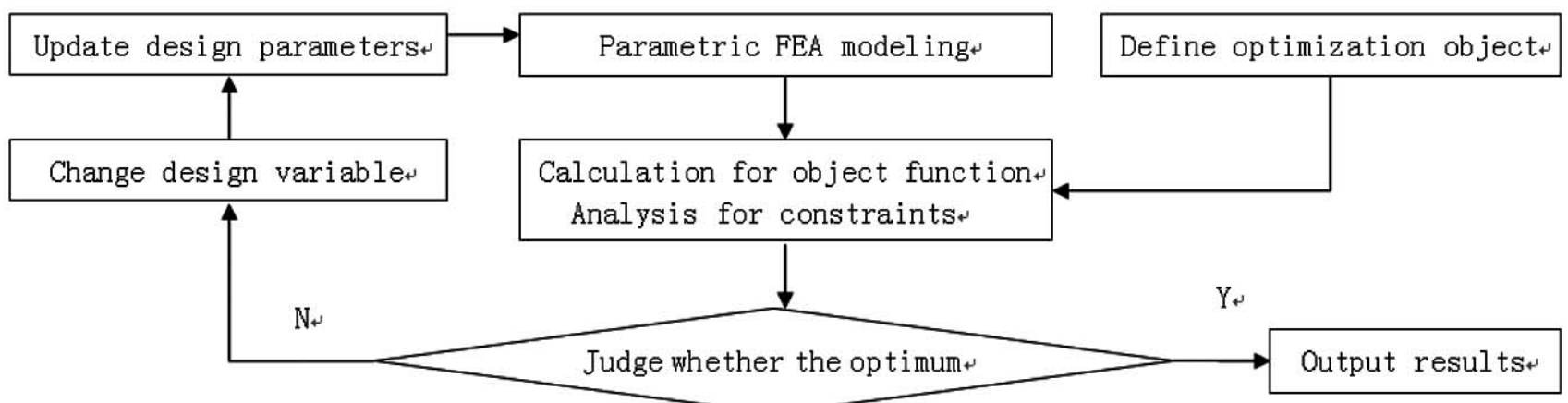

Fig. (5). The process of design optimization.

having to start with the geometric details. Furthermore, design parameters can be changed in the following design process and then design object will be automatically updated. Given any set of geometric parameters, the geometric modeling, meshing, strain and stress analysis can be automatically carried out in sequence.

\section{OPTIMIZATION DESIGN FOR COMPOSITE WING STRUCTURE OF MINITYPE UAV}

\subsection{Description of the Wing Structure Optimization}

In order to reduce the mass of wing, the optimization design principle is employed to choose the best composites wing structure of minitype UAV in this paper. The process of design optimization is shown in Fig. (5). Optimization object is defined after parametric FEA modeling, and then the calculation for object function is conducted. Meanwhile, the analysis for constraints is conducted. After the results come out, the first thing is to judge whether they are the optimal results; if they are the optimal results, they will be exported; otherwise, the input values of design variables should be changed, in order to automatically update the design parameters according to their corresponding relationship, and then rebuild the geometric model. Thereby, the corresponding FEA model can be reestablished for renewed analysis computation. This cycle continues until the optimal results are available.
The optimization design problem of the minitype UAV composite wing structure is formulated as equation (1).

$$
\begin{aligned}
& \min \quad W(X)=\sum \rho_{\mathrm{j}} * V_{j}(X) \\
& \text { s.t. } \quad\left|\sigma_{1}\right| \leq X^{\prime}, \quad\left|\sigma_{2}\right| \leq Y^{\prime}, \quad\left|\tau_{12}\right| \leq S \\
& \quad d_{\max } \leq 10 \mathrm{~mm}, \quad R_{\max } \leq 1^{\circ} \\
& \quad 0.5 \leq x_{1} \leq 0.99,8 \leq x_{2} \leq 15,0 \leq x_{5} \leq 90,0.01 \leq x_{6} \leq 0.9 \\
& 0.01 \leq x_{7} \leq 0.95, \quad 0.1 \leq x_{8} \leq 30, \quad 0.1 \leq x_{9} \leq 30 \\
& x_{3}=1,2,3,4,5,6, \quad x_{4}=1,2,3,4,5
\end{aligned}
$$

where $W(X)$ is the weight function of the wing; $\rho_{\mathrm{j}}$ is the density of component $\mathrm{j} ; V_{j}(X)$ is the volume of component $\mathrm{j} ; \sigma_{1}, \sigma_{2}$ is the largest positive axis stress occurring in each layer of the wing, $\tau_{12}$ is the largest shear stress of the wing, and $X^{\prime}, Y^{\prime}, S$ are the allowable strength of materials respectively corresponding to $\sigma_{1}, \sigma_{2}$ and $\tau_{12} ; d_{\max }$ and $R_{\max }$ are the maximum deformation and largest torsion angle of the wing, respectively. The design variables $X=\left\{x_{1}, x_{2}, x_{3}, x_{4}, x_{5}, x_{6}, x_{7}, x_{8}, x_{9}\right\}$ are the structure and geometry parameters of the wing. Table 1 lists the design variables and their range. The design objective is to minimize the mass of the wing. The constraints are imposed

Table 1. Descriptions of the Design Variables

\begin{tabular}{|c|c|c|c|c|}
\hline Design vars. & Optimization variables & Variable type & LB \\
\hline \hline$x_{1}$ & Taper ratio & Continuous Real & 0.5 \\
\hline$x_{2}$ & Aspect ratio & Continuous Real & 8.0 \\
\hline$x_{3}$ & Layer number of carbon fibers & Discrete Integer & {$[1,2,3,4,5,6]$} & \multicolumn{2}{|c|}{$[1,2,3,4,5]$} \\
\hline$x_{4}$ & Materials of skin panels & Discrete Integer & 0.09 \\
\hline$x_{5} /\left(^{\circ}\right)$ & Laying angle of materials & Continuous Real & 0.01 \\
\hline$x_{6}$ & Position of front beam & Continuous Real & 0.01 \\
\hline$x_{7}$ & Position of back beam & Continuous Real & 0.9 \\
\hline$x_{8} / \mathrm{mm}$ & Thickness of front beam & Continuous Real & 0.1 & 0.95 \\
\hline$x_{9} / \mathrm{mm}$ & Thickness of back beam & Continuous Real & 0.1 & 30 \\
\hline
\end{tabular}


on the stiffness and strength of the wing structure, the maximum deformation and the largest torsion angle of the wing. Generally, to trade off between minimizing the structure weight and optimizing the structure performance, the number of layers of carbon fibers is considered to be smaller than 7 in the literature. So $x_{3}$ can vary among the six integral (1 to 6). $x_{4} \in[1-5]$ represents the materials of the five most common carbon fiber/epoxy resins (G814NT/3234, G803/ 5224, G827/55, G803/QY891, G827/QY891) used in this work correspondingly [10].

\subsection{Realization of Optimization}

iSIGHT is a software which can carry out system integration, design optimization and automation processing. Through a graphical interface, this software is able to integrate simulation code and provide intelligent support.
The product design period can be significantly reduced; meanwhile, the product quality and reliability can be improved. Therefore, iSIGHT is applied to realize design integration and optimization in our work. The optimization is accomplished in the iSIGHT software.

Genetic algorithm (GA) is applicable to optimization problems with both continuous and discrete design variables. The global optimal solution can be achieved with high possibility. However, it may converge to the vicinity of the optimal point causing inaccurate solution [11-14]. What's more, it suffers heavy calculation burden and slow convergence rate because of too many searching times. Sequential quadratic programming (SQP) is only applied to continuous problems. With fewer reanalysis, it converges quickly, and the accurate optimal solution can be achieved in high efficiency [15].

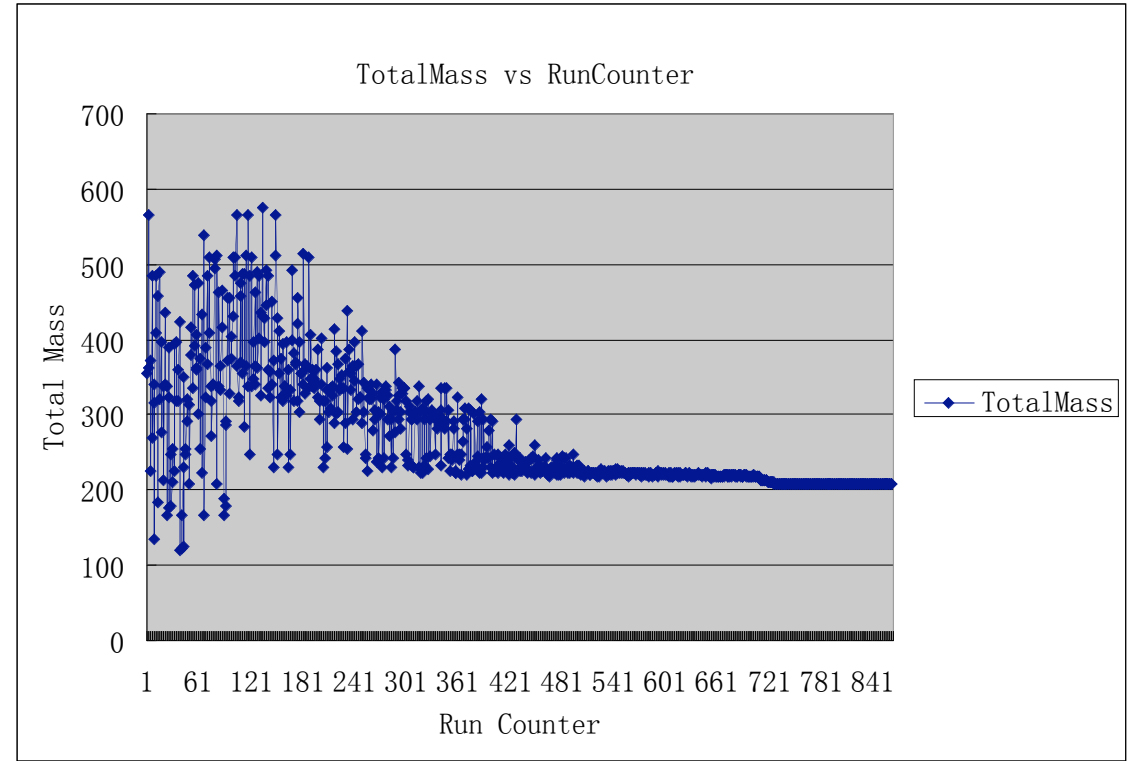

a. Convergence plot of optimization parameter Total Mass.

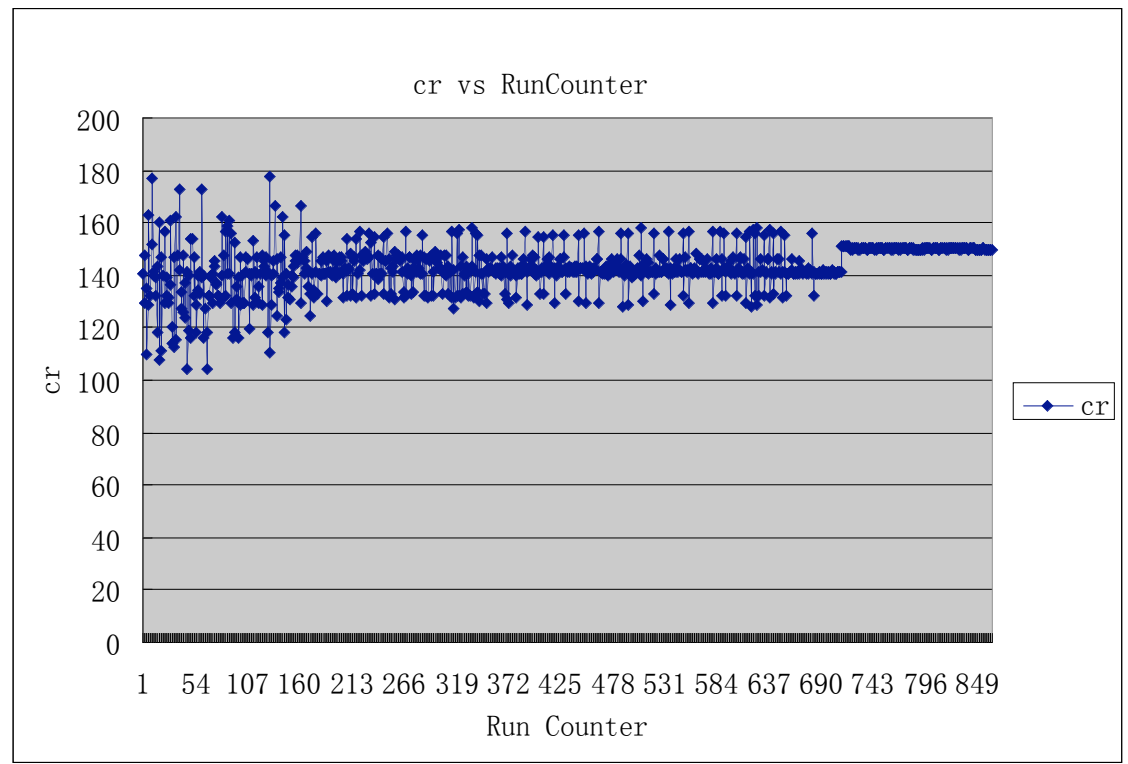

b. Convergence plot of optimization parameter $c_{r}$. 


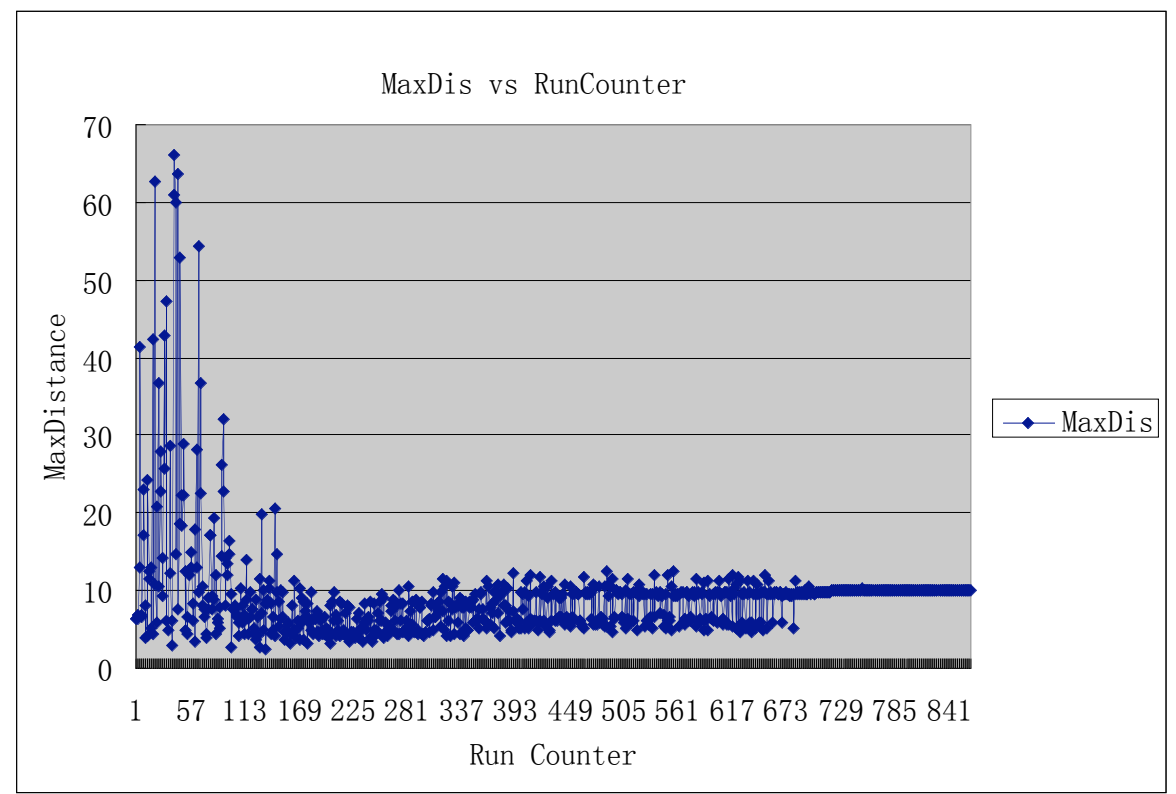

c. Convergence plot of optimization parameter $d_{\max }$.

Fig. (6). Convergence plots of optimization parameters (Total Mass, $\mathrm{c}_{\mathrm{r}}, d_{\max }$ ).

Table 2. Design Variables and System Performances

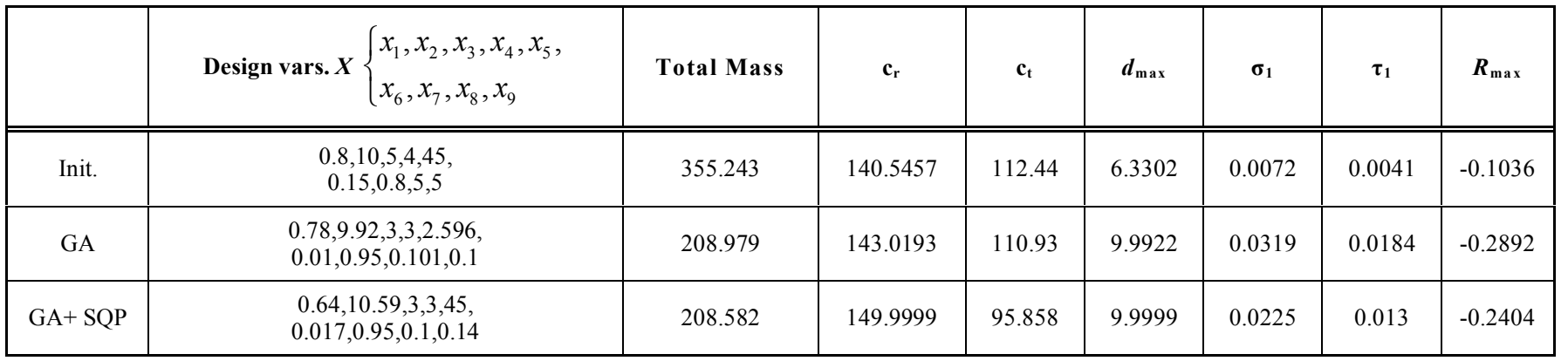

Since both continuous and discrete design variables are involved in this optimization problem, GA is applied. Considering the slow convergence rate and stochastic properties of GA, SQP is used to conduct further optimization search to guarantee the true global optimal solution and improve the convergence rate. GA is first applied to obtain a sub-optimal design point, and then SQP is used to conduct the second round of optimization search with the sub-optimal design point from GA as the initial start point. During this second round, the discrete variables $x_{3}$ and $x_{4}$ are fixed at the values of the sub-optimal design point. In order to investigate the efficiency of our numerical simulation model, another method is carried out for a detailed comparison, in which $\mathrm{GA}$ is alone applied to obtain the optimal design point.

\subsection{Optimization Results Analysis}

In order to verify the effectiveness of our approach, the wing structure performances at the initial start point are also calculated for comparison. Both the initial design variables and optimal ones of these two methods are plugged input into the FEA model to estimate the structure performances. The convergence plots for optimization parameters (Total Mass, $c_{r}$, and $d_{\max }$ ) are depicted in Fig. (6). The design variables and the system performances generated by our approach and those at the initial points are shown in Table 2. To more clearly show the improvement of the optimal design solutions, the stress and displacement distribution at initial point (P0), the optimal point of GA (P1), and the final optimal point of GA+SQP (P2), are also illustrated in Figs. (7, 8 and 9), respectively.

From Table 2 and Figs. (7, 8 and 9) three noteworthy results are drawn below:

(1) The mass of wing is greatly reduced at the optimal design. The Total Mass at the final optimal design point $\mathrm{P} 2$ is $208.582 \mathrm{~g}$, which is reduced by $41.3 \%$ compared to that at the initial design point $\mathrm{P} 0$ (355.243g).

(2) The material can be fully utilized with optimal design. Although, the constraints at both the initial design point $\mathrm{P} 0$ and the final optimal design point P2 

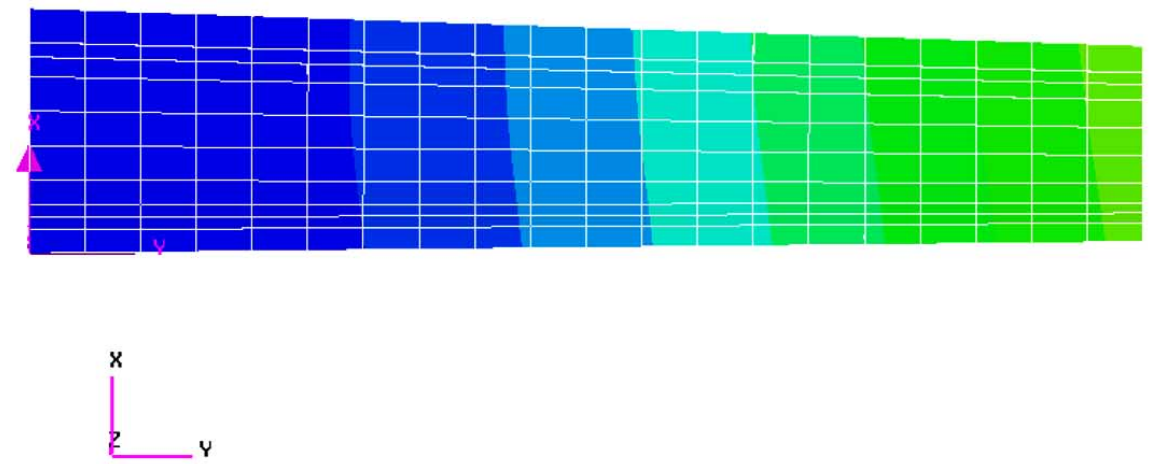

Color Index

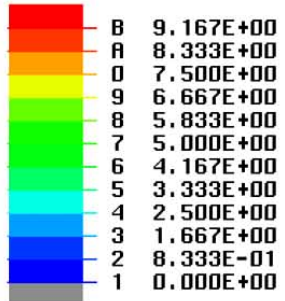

Min $=0.000000 E+000$ Max $=6.330240 E+000$ Min ID $=141$ Max ID= 128 Fringe_1:

Displacements

Trans lational

Magnitude

(NON-LAYERED)

Default

F1: Static Subcase a. Displacement distribution at P0.
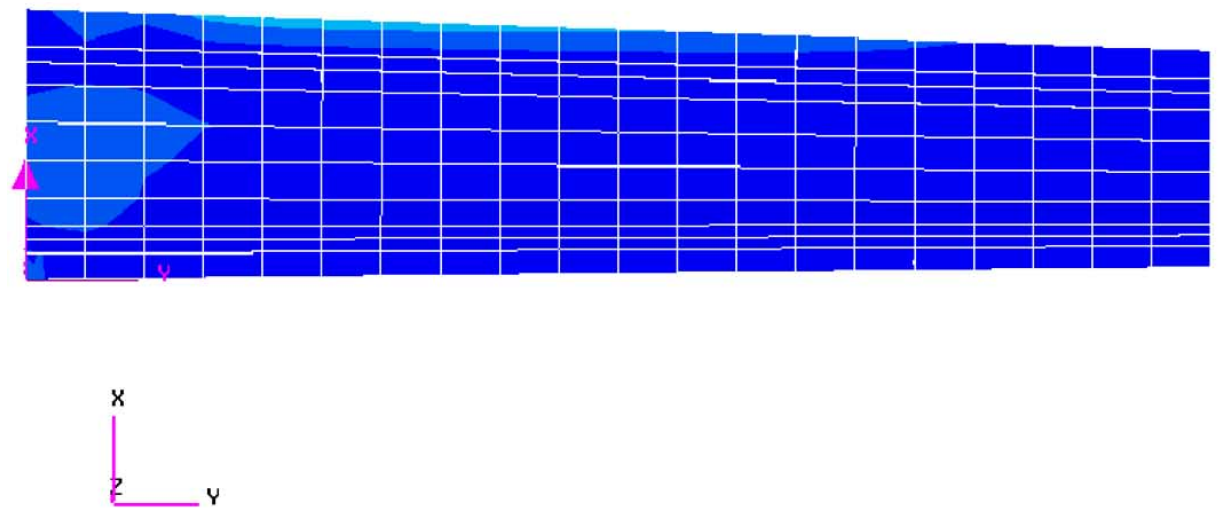

Color Index

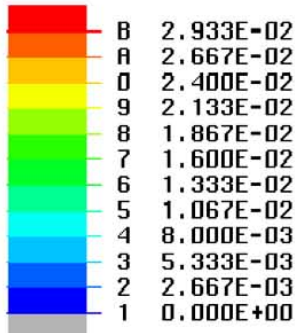

Min $=0.000000 \mathrm{E}+000$ Max $=7.153477 \mathrm{E}-003$

Min ID $=1$

Max ID $=112$

Fringe_1:

Stress Tensor

Uon Mises

(NON-LAYERED)

Default

A1:Static Subcase

b. Stress tensor distribution at P0.

Fig. (7). Stress and displacement distribution at the initial point (P0).

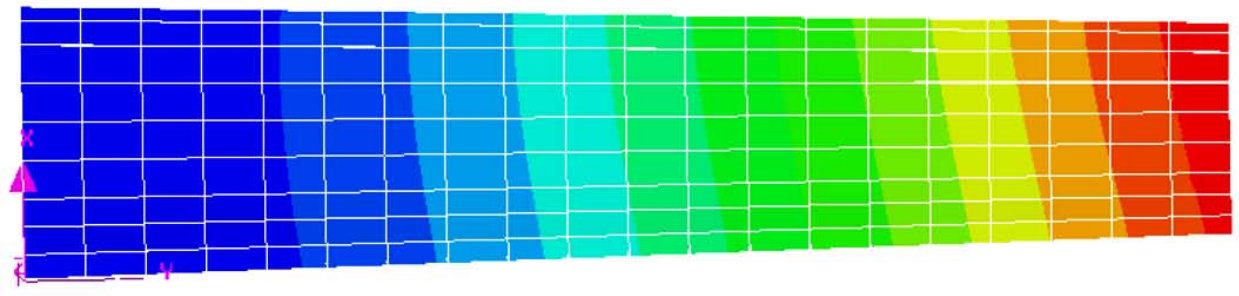

Color Index

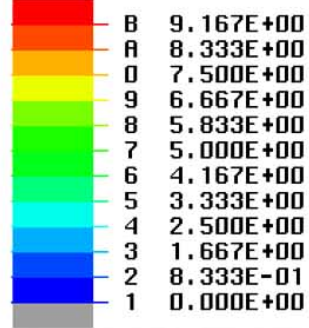

Min $=0.000000 E+000$ Max $=9.992218 \mathrm{E}+000$

Min ID $=141$

Max ID $=259$

Fringe_2:

Displacements

Trans lationa

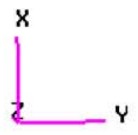

Magnitude

(NON-LAYERED)

Default

F1: Static Subcase

a. Displacement distribution at P1 

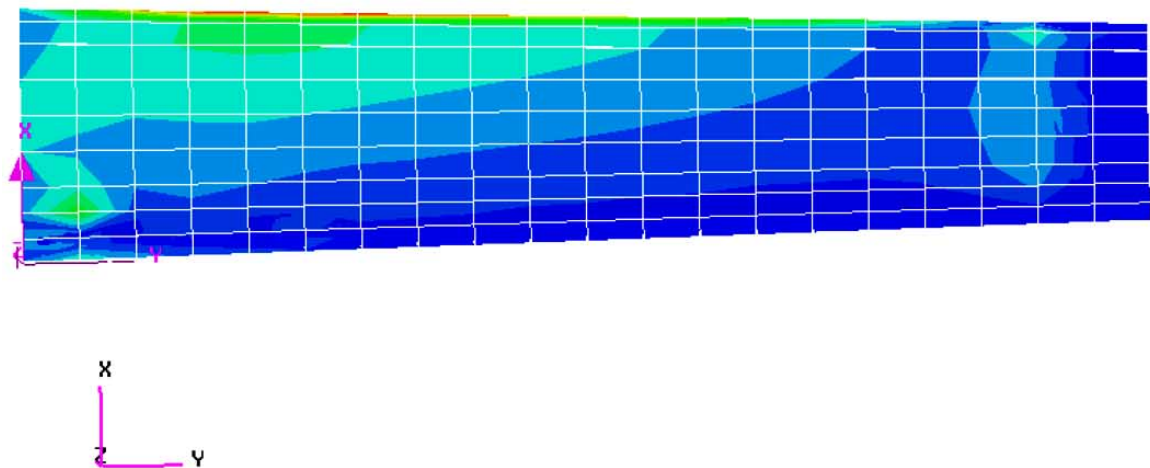

Color Index

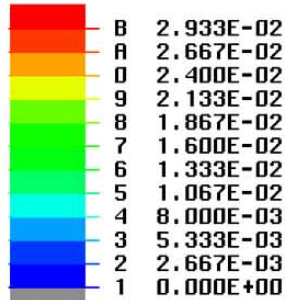

Min $=0.000000 E+000$

Max $=3.196383 \mathrm{E}-002$

Min ID $=1$

Max ID= 766

Fringe_1:

Stress Tensor

Uon Mises

(NON-LAYERED)

Default

A1: Static Subcase

b. Stress tensor distribution at P1.

Fig. (8). Stress and displacement distribution at the GA optimal point (P1).
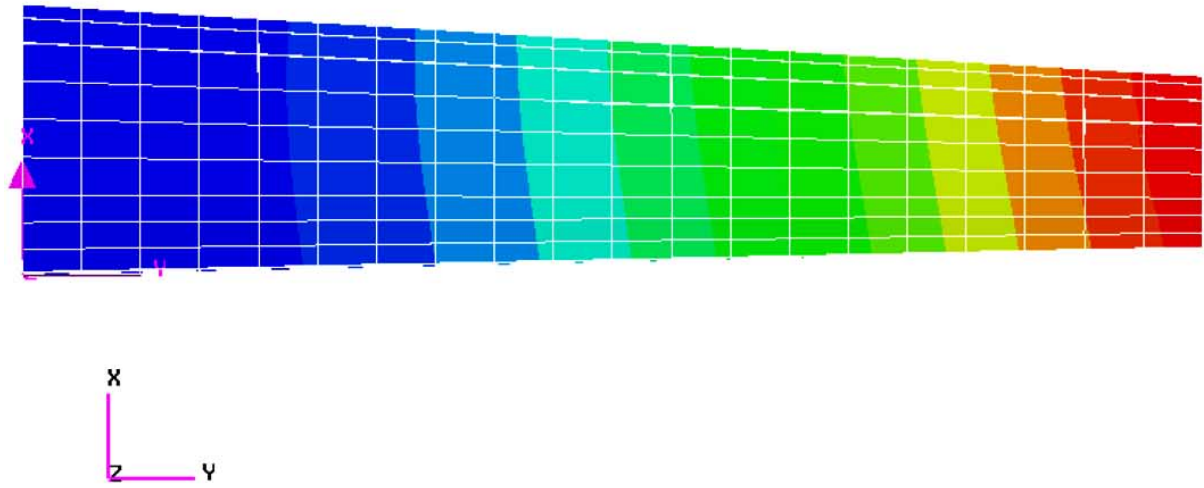

Color Index

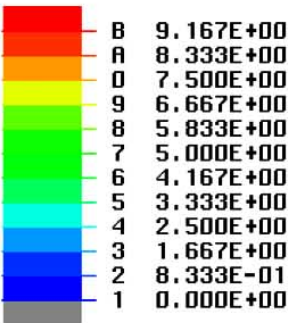

Min $=0.000000 E+000$ Max $=9.999998 E+000$

Min ID= 141

Max ID= 259

Fringe_1:

Displacements

Trans lat iona l

Magn i tude

(NON-LAYERED)

Default

A1:Static Subcase

(Fig. 8) Contd.....

a. Displacement distribution at P2 .
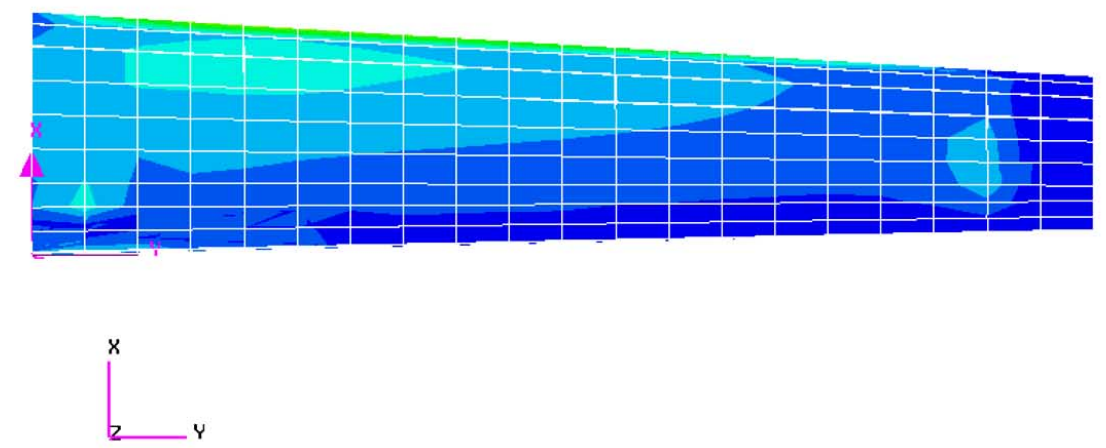

Color Index

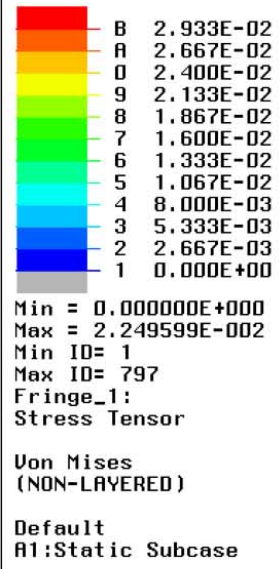

b. Stress tensor distribution at P2.

Fig. (9). Stress and displacement distribution at the GA+SQP optimal point (P2). 
are satisfied, the latter show smaller gap to the constraints upper bound. Just take the maximum deformation as an example, the initial design and the optimal design respectively produce values of $6.3302 \mathrm{~mm}$ and $9.9999 \mathrm{~mm}$ (see in columns 6 in Table 2). It is clear that the optimal design is much closer to the constraint upper bound $(10 \mathrm{~mm})$, which indicates that the material utilization ratio is greatly increased through composites optimization design by our approach. The maximum deformations in Figs. (7a) and (8a) show the same trend.

The Total Mass at the final optimal design point P2 is 208.582g compared to that at the point P1(208.979g). The run time for the GA simulation method was around 12 CPU hours on a Pentium IV 3.0G machine as the data of the optimal point was achieved, and that for our two-step simulation method was only $2.5 \mathrm{CPU}$ hours on the same machine. Moreover, take the length of root chord as an example, the values at P1 and the final optimal design point $\mathrm{P} 2$ are respectively $143.0193 \mathrm{~mm}$ and $149.99 \mathrm{~mm}$ (see in columns 4 in Table 2). It is clear that the final optimal design is much closer to the constraint upper bound (150mm). The final optimal results are significantly improved compared to that of GA, which indicates the effectiveness of our two-step optimization search.

\section{CONCLUSIONS}

The application of the advanced composites plays an important role in improving the aerocraft structure performances. In this work, the parametric finite element model is established to accomplish the stress and strain analysis for UAV composite wings. In the process of optimization, the combination of GA and SQP algorithms ensure that the global optimal solution can be obtained. The optimization results show that the mass of the wing is greatly reduced using our proposed approach, and the utilization rate of material is evidently increased compared to that of the initial design. Meanwhile, the optimization efficiency can be greatly improved with the two-step optimization search strategy.

\section{ACKNOWLEDGEMENT}

The sponsor of National Natural Science Foundation of China (NO. 10972034) and China Poster-doctoral Science Foundation (20100470213) are greatly appreciated.

\section{REFERENCES}

[1] Chinese Institute of Aviation, Composites design manual. Beijing, Aviation Industry Press, 2001

[2] D. Liu, and V. V. Toropov, "Optimization of blended composite wing panels using smeared stiffness technique and lamination parameters", In: 51 $1^{\text {st }}$ AIAA/ASME/ASCE/ AHS/ASC Structures, Structural Dynamics, and Materials Conference, Orlando: Florida, 2010.

[3] N. Chang, W. Yang, J. Wang, and W. Wang, "Design optimization of composite wing box for flutter and stiffness", In: $48^{\text {th }}$ AIAA Aerospace Sciences Meeting Including the New Horizons Forum and Aerospace Exposition, Orlando: Florida, 2010.

[4] O. Seresta, M. M. Abdalla, and Z. Gurdal, "Minimum weight design of composite structures with local postbuckling and blending constraints", In: $47^{\text {th }}$ AIAA/ASME/ ASCE/AHS/ASC Structures, Structural Dynamics, and Materials Conerence, Newport: Rhode Island, 2006.

[5] V. V. Volovoi, S. Yoon, C. Y. Lee, and D.H. Hodges, "Structural optimization of composite rotor blades", In: $45^{\text {th }}$ AIAA/ASME/ ASCE/AHS/ASC Structures, Structural Dynamics \& Materials Conference, Palm Springs: California, 2004.

[6] J.P.T.J. Berends, M.J.L. van Tooren, and D.N.V. Belo, "A distributed multi-disciplinary optimization of a blended wing body UAV using a multi-agent task environment", In: $47^{\text {th }}$ AIAA/ASME/ASCE/AHS/ ASC Structures, Structural Dynamics and Materials Conference, Newport: Rhode Island, 2006.

[7] Aero Model Research Department of Chinese Aviation Club, Model Aircraft Aerofoil Collection. Beijing, People's Sports Press, 1956.

[8] X. N. Mei, "Research of The Multidisciplinary Design Optimization Method for Rocket-Borne UAV", $\mathrm{PhD}$ thesis, Beijing Institute of Technology, Beijing, China, 2010.

[9] S. H. Zhang, X. M. Yu, and E. Johnson, "A practical global optimization procedure", In: $44^{\text {th }}$ AIAA/ASME/ASCE/AHS Structures, Structural Dynamics, and Materials Conference, Norfolk: Virginia, 2003.

[10] S. R. Swanson, "Strength design criteria for carbon/epoxy pressure vessels", J. Spacecr. Rockets, Vol.27, no.5, pp. 522-526, 1990.

[11] T. D. Robinson, K. E. Wollcox, M. S. Eldred, and R. Haimes, "Multifidelity optimization for variable-complexity design". In: $11^{\text {th }}$ AIAA/ISSMO Multidisciplinary Analysis and Optimization Conference, Portsmouth: Virginia, 2006.

[12] J. L. Liu, "Intelligent genetic algorithm and its application to aerodynamic optimizaion of airplanes", AIAA J., Vol. 43, no.3, pp. 530-538, 2005

[13] O. Seresta, M. M. Abdalla, and Z. Gurdal, " A genetic algorithm based blending scheme for design of multiple composite laminates", In: $50^{\text {th }}$ AIAA/ASME/ASCE/AHS/ASC Structures, Structural Dynamics, and Materials Conference, Palm Springs: California, 2009

[14] N. Rastogi, D. K. Ghosh, and G.Vanderplaats, "Discrete optimization capabilities in genesis structural analysis and optimization software", In: $9^{\text {th }}$ AIAA/ISSMO Symposium on Multidisciplinary Analysis and Optimization, Atlanta: Georgia, 2002.

[15] L. Pan, and H. J. Du. "Structure topology optimization for dynamics performance using SQP method", In: $8^{\text {th }}$ AIAA/USAF/ NASA/ISSMO, Symposium on Multidisciplnary Analysis and Optimization, Long Beach: CA, 2000. 